\title{
A Comparison of Research University and Two-Year College Library Web Sites: Content, Functionality, and Form
}

\section{Laura B. Cohen and Julie M. Still}

The authors examined the library home pages of fifty Ph.D.-granting institutions and fifty two-year colleges to determine the home pages' purpose as manifested by their content and its placement within the structure of the site. By looking at the library Web sites of contrasting academic institutions, the authors identified those aspects of the sites that reflect institutional character. They further identified a core common content that exists across academic library Web sites independent of the parent institution.

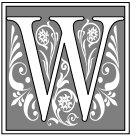

eb sites are becoming a commonplace phenomenon in modern society, and academic libraries have been very much a part of this trend. Academic institutions were early contributors to the Internet experiment, and it has long been a part of campus culture to provide computers that offer access to the resources contained in this global network. It is no surprise that libraries within academic institutions were early developers of Gopher and then Web sites. In recent years, library Web sites overall have undergone a tremendous proliferation. As of October 1998, Libweb, one of the premier Web-based collections of links to library sites, listed nearly 2,500 Web sites in more than seventy countries ${ }^{1}$

Despite the ubiquity of Web sites, both within academic institutions and more re- cently in the social and business world, systematic research that studies the content, structure, and functionalities of these sites is only recently emerging. Three studies from 1996 illustrate the scope of this type of research, especially with respect to libraries. Laurel A. Clyde compared school and public library Web pages in thirteen countries and identified a number of common content attributes among these sites. ${ }^{2}$ She stated that "There are many different reasons or purposes for which a library might create a home page or Web site and to a certain extent these purposes determine the format and content of the page, although most library pages or sites in the studies reported in this article appear to have been created to serve multiple purposes. When this was the case, unless the pages/sites were well organized to lead

Laura B. Cohen is Network Services Librarian at the University at Albany, SUNY; e-mail: LCOHEN@cnsvax.albany.edu. Julie M. Still is Multimedia Instruction Librarian at Rutgers University, Camden; e-mail: still@crab.rutgers.edu. 
people to the appropriate information or resources, the sites or pages could appear confusing and even chaotic." Mark Stove and Steven D. Zink compared the design of the main home page of forty higher education library sites and echoed Clyde's remark about the poor design of some of the sites encountered. They also identified common elements to the main landing page, including the title, name of sponsoring entity, description of purpose, indexing links to content within the site, and contact information. ${ }^{3}$ Jan Whalen studied a small number of college and university library Web sites to assess content. The pages studied featured links to library services, resources on the Web, directions for locating the library, details of access for the disabled, and a few special features such as lists of library instruction classes and a virtual tour of the library.

In 1998, David L. King investigated the main, front-end home page of all $120 \mathrm{ARL}$

\section{It may be assumed that any library mounting a Web site does so within the context of an institution that offers Web access on public workstations or has expectations that a critical mass of its users has Internet access from off-campus.}

library Web sites and identified common elements of the "typical" ARL library home page in the areas of page background, document headers, document footer, graphics, hypertext links, unlinked text, and page length. ${ }^{5}$ Among his findings was the frequent appearance of identifying titles, the <mailto: $>$ tag to the author/creator, text-based hyperlinks to home page content, and text consisting of welcome messages and/or descriptions of hyperlinks. The average main screen contained approximately twenty-two hypertext links.

A useful article on Web page organization was written by Steven W. Sowards, who identified depth criteria to describe the design of ready reference sites of mostly academic library home pages. ${ }^{6}$ Group I sites place all their links on a single page. Group II sites have two layers in which a click on the primary screen connects to one of several secondary pages, which contains links connecting to the resources. Group III sites contain three or more layers of pages in a more complex hierarchy. Sowards further identified subtypes within these three groups.

An academic library functions within the context of its parent institution. This has great implications for what can and cannot be accomplished by a library wishing to sponsor a Web site. The mounting and maintaining of a professional Web site of any kind can require a considerable allocation of resources. This can include investment in hardware, software and network access for one's constituency, end-user training and support, staff time and expertise for content development and maintenance, and development and maintenance of the infrastructure that hosts the site. ${ }^{7}$

It may be assumed that any library mounting a Web site does so within the context of an institution that offers Web access on public workstations or has expectations that a critical mass of its users has Internet access from off-campus. It also may be assumed that such libraries create sites in the expectation that they will provide information helpful to, and wanted by, their constituents.

Given this context, the investigators began this study with the knowledge that the nature and size of academic institutions are reflected in the nature and size of their libraries. This, in turn, should be manifested somehow in their libraries' Web sites. The purpose of the current study was to investigate the academic library Web sites of contrasting institutions in order to analyze any similarities and differences between them in three major areas: the purposes these Web sites serve as manifested by their content; the functionalities offered; and the structure of the sites. A study of this type has not been done.

The authors chose to compare the Web sites of Ph.D.-granting research universities and two-year colleges because these may be seen as two ends of the institutional 
spectrum. An investigation of this type would lend itself to the identification of those aspects of a library's Web site that reflect institutional character. Further, such a study in contrasts would be helpful in identifying a core common content that may exist across academic library Web sites, independent of the parent institution.

A brief profile of one school of each type investigated in this study illustrates the contrast. For example, the University of California at San Diego enrolled 18,119 students in 1997 and includes seven separate academic units. The twelve libraries on campus contain a total of 2.3 million books and 23,906 periodical subscriptions. ${ }^{8}$ By comparison, Niagara County Community College enrolled 5,118 students in 1997. The school has one library containing 85,767 books and 538 periodical subscriptions. ${ }^{9}$

Although vastly different in size and scope, both types of institutions are important to higher education. In 1995, there were 3,706 higher education institutions in the United States, 1,462 of which were twoyear schools and 115 were Ph.D.-granting institutions. ${ }^{10}$ Enrollment in Ph.D.-granting institutions totaled 2,999,641, whereas $5,492,529$ students attended two-year schools. ${ }^{11}$ Roughly half of first-year freshmen $(1,017,970$ out of $2,168,831)$ attended a two-year school. ${ }^{12}$ About one quarter (26.38\%) of those attending college in 1995 went to a two-year school. About one third of African-American students (32\%), and more than a third of Hispanic students $(38 \%)$ were enrolled in two-year schools. ${ }^{13}$ There is an overlap in the usage of these institutions in that students may attend a two-year school and later transfer to a larger institution.

This overlap suggests another important reason to compare the Web sites of these two types of institutions. Transfer students often manage to elude library instruction at the larger schools because most general library instruction takes place during freshman year or in conjunction with basic courses. The information provided on library Web sites may be the only type of library orientation that transfer students receive. Previous studies of library services to transfer students were conducted before the advent of Web sites. ${ }^{14}$

\section{Methodology}

To gather the data, one author selected fifty Ph.D.-granting institutions and the other fifty two-year colleges. To cover the greatest possible geographic diversity, the original intention was to choose one library of each type from each state; however, this proved problematic. Therefore, some states are represented by more than one type of library and other states are not represented at all. However, the representation is equal for each state for each type of library. A full list of Web sites examined is available on the Web. ${ }^{15}$

The authors created a worksheet to collect data for each library Web site. They communicated with each other throughout the data collection process, making additional comments on the sheet as serendipitous items of interest were found. The items reviewed can be grouped by category: content, functionality, and structure. Some of the larger, more complex research library sites had links to a dozen or more libraries and affiliated research centers. The investigator took cursory looks at a minimum of two individual libraries' pages but followed through all levels of only one, the most easily identifiable general library (as opposed to smaller subject libraries). Data collection took place during July 1998.

\section{Content}

In addressing the purpose of these library sites as identifiable by their content, the authors asked the following four questions:

1. Is the library Web site an information tool?

A Web site can provide a library with an opportunity to disseminate information about itself. This can include items such as physical address, staff directory, description of services, departments and policies, and announcements of library news and events. A Web site also might provide information about itself. This may take the form of an update date, a contact e-mail link, and a mission statement or disclaimer.

2. Is the library Web site a reference tool? 
The World Wide Web contains a wealth of reference material. One indication of this is the presence of links to reference sources such as biographical information, dictionaries, and subscription encyclopedias. Links to Web-based search engines such as AltaVista and Infoseek were counted, as were links to Web directories such as Yahoo!, The Internet Public Library, the WWW Virtual Library, etc. Some libraries also use their Web sites to provide information on the local and regional area to their constituencies. Finally, links to a library's OPAC and the OPACs of other libraries were included in this category.

3 . Is the library Web site a research tool?

A library Web site can contribute to the library's effort to address the research needs of its academic community. Included in this category are subject bibliographies of Internet resources in academic disciplines (as opposed to general reference). It was assumed that these subject pages were compiled by the library's staff, and noted when a page resided at another institution. Also in this category were pathfinders to locally held resources. These pathfinders may exist first as hard-copy library handouts before being mounted on the Web. With the proliferation of free periodicals on the Web, links to these resources also were identified and counted. Finally, the investigators noted the presence of subscription or paid Web-based services other than encyclopedias, such as the indexes and full-text resources provided by FirstSearch, IAC SearchBank, JSTOR, Lexis-Nexis, and Project Muse.

4. Is the library Web site an instructional tool?

A library Web site is an attractive medium for the dissemination of instructional materials. The investigators looked at Internet/Internet software tutorials, tutorials on the use of the library, and computer software tutorials. Library use tutorials might include instructions on how to use an index, a guide to database search strategies, how to write a bibliography, how to locate articles, elements of the research process, and so on, but not help screens within a given tool. The presence of software tutorials might indicate the blurring of the lines between an academic library and academic computing.

For most of the items described above, the investigators made a count of the number of links included for each-for example, the total number of reference sources linked from a library's Web site. It was sometimes a challenge to identify these sources. On some of the Web sites, reference sources were linked from the same jump-off page as academic subject areas, or mixed in with other types of sources on the same page. Every attempt was made to identify and count resources in any location where they were found. There also were cases in which the same link was made from multiple pages. As the amount of duplication appeared quite small, there was no attempt to avoid a double count.

\section{Functionalities}

To address functionalities, the authors looked at two technologies commonly found on Web sites: the use of a site search engine, and interactive request forms. A site search engine allows the user to enter a search statement that the engine then will process against the files on that site and return a list of hits. The ability to conduct such a search can offer users the opportunity to locate materials of interest without needing to navigate through the site. This is especially useful on large and complex sites such as those provided by some of the research libraries. Interactive request forms allow users to submit various types of requests by filling out a template and submitting the form. Examples for library Web sites include requests for interlibrary loan (ILL) and the purchase of library material.

\section{Structure}

A Web site has a structure, or architecture, that consists of a main landing screen, or page, and sfghyui90-pages that are accessed via hyperlinks from the main page. Beyond the main page, a Web site can include different types of information structures. ${ }^{16}$ Because of the hypertext nature of the Web, this structure can be quite complex. A particular page or function may be approachable from multiple locations 
within the same site. For example, an OPAC may be linked from several pages within a library's site. The authors recorded the topmost appearance of each item investigated (i.e., the level closest to the main page). This would reveal the amount of navigation away from the main page that was necessary to access a particular item. In many cases, multiple access points throughout the site also were noted.

Site architecture across six levels were examined, starting with the main screen:

- Main Screen: An item appeared on the landing page.

- Level 1: An item was linked from the landing page.

- Level 2: An item was linked from a subsequent page;

and so on to level5. At this distance from the main page, very few resources made a first appearance. In fact, two-year college Web sites rarely reached this level of complexity, whereas on some research library sites users do not begin to access the actual content of branch library pages until reaching level 3, and new content could appear several levels below that.

\section{Results}

\section{Content}

Every item investigated appeared on the Web sites studied, and all but one appeared on the sites of both types of schools. Table 1 shows the total number of library Web sites that contained the resources studied. A fuller picture was achieved by looking at the total number of occurrences of individual items in the reference, research, and instruction categories. To assist in comparisons, the totals for selected resource types were organized into clusters (e.g., 1-5 items, 6-10 items, and so on). These totals illustrated the degree to which the items were covered. These data are presented in tables 2 and 3 . Taken together, these tables provided answers to the four questions about the purposes these academic library Web sites serve.

The study's first question asked whether the Web site served as an information tool. Most of the Web sites studied provided some degree of information about their libraries. The most prevalent information of- fered was a contact e-mail link, a Web page update date, and a description of services.

More than half of the research libraries included all the items except a Web page statement and separate description of policies. Measuring a separate description of services, departments, and policies turned out to be unrealistic for the research libraries because these descriptions usually appeared together in various combinations. The actual coverage for policies, therefore, was higher than the separate number indicates.

It was striking to note that only five $(\mathbf{1 0 \%})$ libraries of each type included a mission statement or disclaimer about their Web sites.

More than half the two-year college libraries included a contact e-mail link, update date, staff directory, description of policies, and description of services. Given the small size of these organizations, it was no surprise that only two of these libraries offered departmental descriptions. Moreover, there was very little coverage of library news and events (nine, or 18\%). Although this may be surprising from a public relations point of view, it might make sense when considering the staff time needed to keep such an item current. Of the thirty-five two-year college library sites that provided an update date, six had last been updated ten or more months prior to the investigator's visit. This also may be a factor in the relative sparsity of news and events information.

It was striking to note that only five $(10 \%)$ libraries of each type included a mission statement or disclaimer about their Web sites. Thus, these libraries allow the public to make assumptions about the mission of their sites, which may be contrary to the libraries' intent, and also overlook the opportunity to publicly absolve themselves of any liability as to their sites' content or the content linked from their sites. This also may be an indication that, as many case studies have shown, it is not uncommon for library Web sites to be a "bottomup" project, begun because someone on the 
TABLE 1

Total Web Sites Containing Resources

\begin{tabular}{|c|c|c|c|c|}
\hline Resource & Ph.D. & Percentage & Two-Year & Percentage \\
\hline \multicolumn{5}{|l|}{ Library information } \\
\hline Web page statement & 5 & 10 & 5 & 10 \\
\hline Contact email link & 50 & 100 & 39 & 78 \\
\hline Physical address & 30 & 60 & 24 & 48 \\
\hline Update date & 44 & 88 & 35 & 70 \\
\hline Staff directory & 36 & 72 & 26 & 52 \\
\hline News/Events & 44 & 88 & 9 & 18 \\
\hline Description of departments & 32 & 64 & 2 & 4 \\
\hline Description of services & 40 & 80 & 44 & 88 \\
\hline Description of policies & 15 & 30 & 36 & 72 \\
\hline \multicolumn{5}{|l|}{ Reference } \\
\hline Links to search engines & 38 & 76 & 32 & 64 \\
\hline Links to Net directories & 22 & 44 & 23 & 46 \\
\hline Reference section & 39 & 78 & 37 & 74 \\
\hline Links to own OPAC & 50 & 100 & 42 & 84 \\
\hline Links to other OPACs & 44 & 88 & 33 & 66 \\
\hline Links to local info & 23 & 46 & 25 & 50 \\
\hline Subscription encyclopedia & 41 & 82 & 14 & 28 \\
\hline \multicolumn{5}{|l|}{ Research } \\
\hline Links to Net subject resources & 42 & 84 & 30 & 60 \\
\hline Pathfinders to local resources & 30 & 60 & 5 & 10 \\
\hline Links to subscription services & 49 & 98 & 36 & 72 \\
\hline Links to free periodicals & 23 & 46 & 19 & 38 \\
\hline \multicolumn{5}{|l|}{ Instruction } \\
\hline Net/Net software tutorials & 10 & 20 & 26 & 52 \\
\hline Library use tutorials & 21 & 42 & 14 & 28 \\
\hline Software tutorials & 0 & 0 & 3 & 6 \\
\hline \multicolumn{5}{|l|}{ Functionalities } \\
\hline Request forms & 35 & 70 & 15 & 30 \\
\hline Search engine & 29 & 58 & 3 & 6 \\
\hline
\end{tabular}

staff had the knowledge to do so, not because library administration (or anyone else) developed a mission or guidelines for the site. Such a statement may come later or not at all.

The second question asked was whether the library Web site served as a reference tool. Again, all the items studied appeared on the Web sites of both types of institutions. Most prevalent were links to a library's own OPAC. All the research libraries and 84 percent of the two-year college libraries offered these links. There also was a high occurrence of links to the OPACs of other libraries, with 88 percent of the research libraries and 66 percent of the two-year college libraries making these links. Two of these two-year college sites linked to extensive meta-sites of OPACs compiled at remote libraries, whereas two others linked to meta-sites created by consortia of which they were members. Most two-year college library sites linked to ten or fewer other OPACs. Many of the research libraries also linked to meta-sites such as the Libweb site mentioned earlier. Another common theme was a link or links to the OPAC of other libraries in the geographic area, although not necessarily as part of a consortium.

Almost an equal number of these libraries, thirty-nine research libraries and thirtyseven two-year college libraries, either offered a separate section of reference sources or included reference links on their 
sites. The degree of coverage, however, tells a more complete story. Overall, the twoyear college libraries did a minimal job of providing access to reference sources on the Web. As table 3 demonstrates, fifteen of the thirty-seven libraries that included reference sources linked to twenty or fewer of them, whereas only eight linked to more than 100 . Five of these libraries relied primarily on reference pages located on other libraries' Web sites. This practice can be beneficial to libraries without the resources to produce an extensive listing on their own. An interesting example was the compilation of reference links at the DelAWARE site, created as a joint project of the Delaware Division of Libraries, Delaware Public Libraries, and Delaware Technical \& Community College. ${ }^{17}$

Both types of libraries were more likely to link to Internet search engines than to Internet directories. Seventy-six percent of

TABLE 2

\section{Clusters of Total Resources for Ph.D. Schools}

\begin{tabular}{lccccccccc} 
Resource & \multicolumn{1}{l}{ Clusters of Total Links } \\
\hline Reference & $1-20$ & $21-40$ & $41-60$ & $61-80$ & $81-100$ & $101-150$ & $151-200$ & $201-250$ & $251-300$ \\
\hline Links to & 6 & 2 & 3 & 5 & 4 & 10 & 4 & 2 & 2 \\
reference sites & & & $1-5$ & $6-10$ & $11-15$ & $16-20$ & $21+$ & & \\
\hline Links to search engines & 5 & 23 & 5 & 4 & 1 & \\
Links to Net directories & 16 & 5 & 0 & 1 & 0 & \\
Links to other OPACs & 15 & 19 & 3 & 2 & 5 & \\
Links to local info & 9 & 6 & 5 & 0 & 3 & \\
Research & $1-5$ & $6-10$ & $11-15$ & $16-20$ & $21+$ & \\
\hline Links to Net subject resources & 2 & 3 & 3 & 2 & 32 & \\
Pathfinders to local resources & 2 & 1 & 2 & 1 & 24 & \\
Links to subscription services & 0 & 1 & 1 & 3 & 44 & \\
Links to free periodicals & 3 & 3 & 3 & 0 & 12 & \\
\end{tabular}

TABLE 3

Clusters of Total Resources for Two-Year Schools

\begin{tabular}{lccccccccc}
\hline \hline Resource & \multicolumn{7}{c}{ Clusters of Total Links } \\
\hline Reference & $1-20$ & $21-40$ & $41-60$ & $61-80$ & $81-100$ & $101-150$ & $151-200$ & $201-250$ & $251-300$ \\
\hline Links to & 15 & 3 & 6 & 3 & 2 & 5 & 1 & 1 & 1 \\
reference sites & & & & & & & & \\
& & $1-5$ & $6-10$ & $11-15$ & $16-20$ & $21+$ & \\
\hline Links to search engines & 6 & 15 & 5 & 3 & 3 & \\
Links to Net directories & 14 & 4 & 3 & 2 & 0 & \\
Links to other OPACs & 21 & 6 & 1 & 2 & 3 & \\
Links to local info & 11 & 3 & 2 & 2 & 7 & \\
Research & $1-5$ & $6-10$ & $11-15$ & $16-20$ & $21+$ & \\
\hline Links to Net subject resources & 15 & 3 & 6 & 1 & 5 & \\
Pathfinders to local resources & 2 & 2 & 1 & 0 & 0 & \\
Links to subscription services & 27 & 5 & 3 & 0 & 1 & \\
Links to free periodicals & 10 & 5 & 2 & 0 & 2 & \\
Instruction & $1-5$ & $6-10$ & $11-15$ & $16-20$ & $21+$ & \\
\hline Net/Net software tutorials & 16 & 5 & 0 & 2 & 3 & \\
Library use tutorials & 10 & 3 & 1 & 0 & 0 & \\
Software tutorials & 3 & 0 & 0 & 0 & 0 & \\
\hline
\end{tabular}


the research libraries made links to search engines, as did 64 percent of the two-year college libraries. Links to Internet directories appeared on only 44 percent of the research library pages and 46 percent of the two-year college pages. It was notable that all of the libraries that linked to Internet directories pointed to twenty or fewer directories; most in both categories linked to five or fewer. A number of the Web sites of both types of libraries presented inaccurate lists of search engines by including the Yahoo! directory. This was the case with eleven research libraries and nine two-year college libraries.

The popularity of Web-based subscription encyclopedias was especially striking for the research libraries, 82 percent of which had links to this type of resource. In contrast, only 28 percent of the two-year college libraries linked to a subscription encyclopedia. By far the most popular encyclopedia was Britannica. This subscription was represented on thirty-eight research library sites and eleven two-year college library sites. There also was a scattering of subscriptions for Cambridge Encyclopedia, Encyclopedia Americana, Academic American Encyclopedia, Grolier's, and Encarta. It was unusual for a site to link to more than one subscription encyclopedia. Only four Web sites of research libraries and one two-year college site linked to more than one subscription.

About half these libraries used their Web sites to provide links to local or regional information. Of those providing links of this type more than half offered fewer than ten links.

Another aspect of a Web site's effectiveness as a reference tool is its offering of annotations. It is one thing to make a link; it is quite another to supply a descriptive or evaluative blurb about the linked-to site. Such an annotation can provide a helpful guide to users as they scan lists of links and choose those sites they wish to visit. Table 4 demonstrates that annotations were in short supply on the pages investigated. For example, only fourteen of the thirty-six research libraries (39\%) linking to search engines annotated these links. Nine of thirty- two (28\%) two-year college libraries annotated these links. The situation was more extreme for Internet directories. Four of twenty-nine research libraries (14\%) annotated these links, compared with six of twenty-three (26\%) two-year college libraries. These resources vary significantly from one another, but users of these library Web sites are being left to discover the differences for themselves without the benefit of a librarian's assessment. A similar situation held true for the links to reference sources. Six of forty-one research libraries (15\%) linking to reference sources annotated these links, whereas twelve of thirtysix $(33 \%)$ two-year college libraries made annotations. Although a few libraries (more often research libraries) included a section on evaluating search engines in their library tutorials, these screens usually were not linked to the search engines page. Likewise, tutorial sections on evaluating Web materials in general usually are not accessible, or even mentioned, from any other point than the tutorial itself.

The third question asked whether the library Web site served as a research tool. As might be expected, the Web sites of research institutions did well in this category. Subscription database services, often purchased through consortia or on a systemwide basis, were a major avenue for offering Web-based research materials to both types of libraries. Table 1 shows that forty-nine research libraries provided links to subscription database services, forty-four of which linked to more than twenty-one of these tools. Among the two-year college libraries, thirty-six offered these services, twenty-seven of these subscribing to five or fewer services. Two of the libraries were members of OhioLink and The Virtual Library of Virginia (VIVA), consortia that offered them access to twenty or more subscriptions. The efforts of such large consortia offer these schools a tremendous wealth of Internet-based research tools. It was interesting to note that a number of these sites acknowledged the consortial arrangement. Further, two-year college library sites were more likely to link to subscription services by name (i.e., FirstSearch, SearchBank, 
etc.) than research library sites, which tended to link to the individual databases contained in these services, sometimes within larger lists of free databases and journals, arranged alphabetically, by subject, or other combination. At some sites, especially the two-year college sites, it is possible to determine what services, or vendors, the databases were purchased from by running the computer mouse over the link. Many research libraries, however, have loaded the databases directly on their server so that the mouse displays a local link and not a link to the vendor.

Another popular avenue for providing research materials was the mounting of discipline-specific pages of links to Internet resources created by library staff. Forty-two $(84 \%)$ research libraries offered such pages, thirty-two of which created pages in more than twenty subject areas. Thirty $(60 \%)$ of the two-year college libraries offered discipline-specific pages of links to Internet resources, half of these providing pages in five or fewer subject areas. Four of these libraries relied on subject pages created at other libraries. Although not counting the number of links on these subject pages, one investigator noted that pages created by library staff in these two-year colleges usually contained a very small number of links, sometimes only a handful for each subject area. The size and complexity of these resources at research libraries varied greatly. Although a number of subject areas were represented, some of these sites linked to only a few individually chosen tools; others linked to multiple meta-sites compiled at other institutions. This is not always evident from the resource page unless one checks the address of each link individually. Given the enormity of this task, for the purposes of this study only the number of links was counted and not necessarily the type of link (local or remote meta-site).

Although many libraries included Internet subject lists on their sites, there were variations on the use of annotations. Fifteen of thirty two-year college libraries included annotations (table 4). A correct number was more difficult to establish for the research libraries and thus is not included in table 4 . Because the Internet subject resource lists may be on individual library pages instead of subject pages or may be compiled by librarians from the various libraries, there is very little consistency within institutions, and sometimes within pages. The listings on one subject page may be annotated, but those on another may not be; or some individual items on a list are annotated and others are not. Those libraries with a clear, consistent policy would appear to have decided against annotations. This is yet another example of the way the complex organization of the research university impacts on the libraries and, therefore, on Web page organization.

Pathfinders to locally held resources were less common, appearing on 60 percent of the research library sites and only 10 percent of the sites for two-year colleges (table 1). Many of the research libraries that offered path-

\begin{tabular}{|lccc|}
\hline \multicolumn{3}{c|}{$\begin{array}{c}\text { TABLE 4 } \\
\text { Annotations }\end{array}$} \\
\hline \hline Resource & Total & Annotated & Percentage \\
\hline Ph.D. & & & \\
Links to search engines & 36 & 14 & 39 \\
Links to Net directories & 29 & 4 & 14 \\
Links to reference sites & 41 & 6 & 15 \\
Links to own OPAC & 50 & 10 & 20 \\
Links to other OPACs & 43 & 10 & 23 \\
Links to local info & 24 & 2 & 8 \\
& & & \\
Two-Year & & & \\
Links to search engines & 32 & 9 & 28 \\
Links to net directories & 23 & 6 & 26 \\
Links to reference sites & 36 & 12 & 33 \\
Links to own OPAC & 42 & 1 & 2 \\
Links to other OPACs & 33 & 1 & 3 \\
Links to local info & 25 & 3 & 12 \\
Links to Net subject resources & 30 & 15 & 50 \\
\hline
\end{tabular}


finders, however, did so as a significant effort. Twenty-four of the thirty libraries mounting this type of resource offered pathfinders in more than twenty research areas. By contrast, four of the five two-year college libraries offering pathfinders did so in ten or fewer areas. It was interesting to note that twenty-three research library sites offered both subject resource pages and pathfinders, and only two offered neither. The overall sparsity of pathfinders was surprising, especially in the case of two-year college libraries. Most libraries offer printed pathfinders of some form or another. Given that many word processors now have the capability of saving text documents as HTML files, it would be relatively easy to produce at least a few pathfinders as Web documents. The lack of Web-enabled pathfinders, however, may be an indication of staffing level rather than ability. It is possible that at many libraries either no one has had the time to do this or the library administration has not made it a priority.

\section{Some of the research libraries presented separate listings for subscription electronic journals and free titles, and others organized them all in one long listing.}

Forty-six percent of the research libraries and 38 percent of two-year college libraries took advantage of the free periodicals on the Web by linking to them (table 1). Twelve of the research libraries linked to more than twenty of these periodicals, whereas ten of the two-year college libraries linked to five or fewer. One notable exception was the two-year college library that linked to the Web site of every periodical it owned that maintained a site; this amounted to more than 200 links.

Some of the research libraries presented separate listings for subscription electronic journals and free titles, and others organized them all in one long listing.

Because some Web-accessible OPACs now have the capability of including links within their catalog records, it is possible that some libraries have cataloged certain free electronicjournals and included links there, instead of compiling a separate listing (although some libraries have done both).

Finally, this study investigated whether the library Web sites served as an instructional tool. The picture here was somewhat mixed. The two-year college libraries offered Internet or Internet software tutorials more frequently than research libraries, 52 percent as compared with 20 percent. Given the greater division of duties at larger schools, it is possible that Internet-related tutorials are available, but on the computer center's site instead of the library's site. Of the ten research libraries that offered these tutorials, half linked to tutorials created by other libraries. Nineteen of twenty-six two-year college libraries did the same. Even so, sixteen of these libraries linked to five or fewer of these tutorials. Library use tutorials were mounted by 42 percent of the research libraries and 28 percent of the two-year college libraries (table 1). Of the fourteen two-year college libraries offering these tutorials, ten mounted five or fewer. The preponderance of library use tutorials on the research library sites suggests that large, complex libraries or library systems create the need for tutorials, have the staff to create these tutorials, and are oriented toward publishing tutorials on the Web. It is useful to note that the availability of these tutorials can benefit transfer students who miss out on formal library orientations or instruction.

If librarians are taking on the role of teaching computer software, they are not mounting these tutorials on the Web. None of the research libraries mounted software tutorials, compared with only three twoyear college libraries. Once again, it is possible that these tutorials are available elsewhere in the institution's Web structure.

\section{Functionalities}

It was no surprise that a greater number of research library sites offered Web-based functionalities than did two-year college library sites. It may be assumed that research libraries have access to larger academic computing units with more resources to exploit and share, or they may have the technol- 
ogy and staff to implement these functionalities themselves. Interactive request forms were present on the sites of 70 percent of these libraries, the most common type being ILL. Fifteen sites $(30 \%)$ of the two-year college libraries offered interactive request forms. Found in almost equal numbers were forms for ILL, requesting an item for purchase, asking a reference question, and submitting a comment to library staff.

A search engine was offered on 58 percent of the research library sites. As some of these Web sites were of substantial size, the search engine was an appropriate offering. The smaller sites of the two-year college libraries had little need of a search engine. This was reflected in the fact that only three of these sites offered one.

\section{Site Structure}

It was immediately apparent that the type of school had a dramatic impact on the size and arrangement of the Web site. Two-year college library sites encompassed the main page through three levels down, with the second and third levels introducing little new material. Only one resource type-free electronic journals-extended as far as four levels away from the main screen on just one library site, and these were linked from subject resource pages that were organized from levels 2 and 3.

It was notable that some of the two-year college sites were extremely small. Four of them consisted of only one page, one of two pages, and three of three pages; these accounted for 16 percent of the two-year college sites studied. On these limited sites, the main screen served an extremely important function. For example, one library site placed all thirteen links to reference sources on the main screen, and another did the same with its eleven reference links. Two of the other smaller sites also placed all of their reference links on the main page. This is in contrast to the more usual practice on larger sites of placing one link to reference sources on the main screen, with the links to individual sites appearing at the next one or two levels down. These links were recorded as level 1 in both situations because they were linked from the main screen, but it is useful to note that four small two-year college sites used their main screen as a catch-all for most, if not all, of their resources.

Certainly the main screen of any Web site serves a vital function. When looking at the research and two-year college library sites together, it can be seen that this landing page serves two major functions: (1) as an index with links to information located on subsequent pages as represented by level 1 in this study, and (2) as a container of information. Its function for level 1 linkages has been discussed earlier in this section. Looking at the main page as a container, the researchers found that the twoyear college Web sites made a somewhat greater use of this page to present information. This may be seen as a reflection of the smaller, less hierarchical nature of these sites. Table 5 shows the comparison of the use of the main screen for both types of libraries. Only items categorized as library information were found here. It is notable, for example, that three two-year college sites described their policies here, six described their services, and four placed their staff directory on the main page. None of the research library sites used the main page for these purposes. Use of the main page for placement of the update date and physical address was common for both library types. These latter findings are in general agreement with those of King in his study of ARL library sites.

The two-year college library sites, therefore, were organized primarily around the main screen and then one level down as linked from this page. Links from the main screen, as represented by level 1 , accounted for a significant presentation of the content of these two-year college library sites. All of the content relating to reference, research, and instruction appeared on level 1 on at least 65 percent of the library pages offering this content. This is illustrated in table 6.

Some two-year college libraries created sites for limited purposes. The most barebones site consisted of a description of library services. Another contained a description of library services, a staff directory, and a link to an EBSCO database. Yet 
another contained a description of services, links to thirteen reference sites, a link to its own OPAC and to two other OPACs, and links to two local sites. These pages served the functions of information, reference, and research, but only in the most minimal way. Seven other libraries were similarly limited in scope.

Research library Web sites, on the other hand, tended to be very complex and often were reflective of the complexity of the institution. Some sites were easy to navigate, but others were labyrinthine in nature and difficult to maneuver without getting lost. Most of the institutions studied had more than one library, and thus the main screen primarily included materials that were applicable systemwide along with links to individual library pages. These individual library pages also included links back to the main screen or to items included on it (such as the OPAC). Thus, there was initial duplication and cross-linkage. Update dates at some institutions were not given on the main page, but only on secondary and subsequent pages. Pathfinders and staff directories were often on the individual library pages, not on the system main screen. Sometimes pathfinders or guides to Internet resources were located on the Reference Department home page of an individual library, thus appearing in this study as level 3, while it would be located at level 2 to someone starting at that library's page and level 1 for someone who had bookmarked the departmental page. Moreover, there was clearly a lack of systemwide Web policies, as some libraries at the same institution included items (such as pathfinders) that others did not. Further, there was little uniformity of arrangement.

Items on the relatively

Ph.D.

Update date

Staff directory

News/events

\section{Two-Year}

Update date

News/events larger Web sites of research libraries were more evenly distributed through level 3 and thus were more hierarchical. Items appearing most significantly on level 1 (i.e., linked from the main screen) were a contact e-mail link, the library's OPAC, request forms, and the site search engine. Table 7 shows the items that were linked from the main screen by more than half the research libraries offering these items.

It was notable that all of the research library sites presented instructional materials starting at level 2 and beyond. For example, four of ten libraries offering Internet tutorials presented them on level 2, whereas nine of the 21 sites offering library use tutorials placed them on this level. This is related to the arrangement of these sites using the main screen as a systemwide screen. It was rare to find instructional material at this level; it was most often linked off of an individual library's page, perhaps reflecting a lack of systemwide agreement on the use or importance of general library instruction. Another factor may be that librarians develop instructional ma-

\begin{tabular}{c} 
TABLE 5 \\
Use of Main Screen \\
\hline \hline
\end{tabular}

Resource Total Total Main Percentage

Web page statement

Contact email link

$5 \quad 1$

20

Physical address

50

30

44

36

44

Description of departments 32

Description of services

40

Description of policies

15

$\begin{array}{rr}1 & 20 \\ 0 & 0 \\ 16 & 53 \\ 25 & 57 \\ 0 & 0 \\ 5 & 11 \\ 0 & 0 \\ 0 & 0 \\ 0 & 0\end{array}$

Web page statement

Contact email link

Physical address

Staff directory

Description of departments

Description of services

Description of policies
0

53

57

0

11

0

0

0

\begin{tabular}{rr}
3 & 60 \\
0 & 0 \\
11 & 46 \\
34 & 97 \\
4 & 15 \\
0 & 0 \\
0 & 0 \\
6 & 14 \\
3 & 8 \\
\hline
\end{tabular}




\section{TABLE 6}

Links from Main Screen (Level 1) by Two-Year Schools

\begin{tabular}{|c|c|c|c|}
\hline Resource & Total & Total Level 1 & Percentage \\
\hline \multicolumn{4}{|l|}{ Library Information } \\
\hline Web page statement & 5 & 2 & 40 \\
\hline Contact email link & 39 & 36 & 92 \\
\hline Physical address & 24 & 7 & 29 \\
\hline Update date & 35 & 0 & 0 \\
\hline Staff directory & 26 & 19 & 73 \\
\hline News/events & 9 & 9 & 100 \\
\hline Description of departments & 2 & 1 & 50 \\
\hline Description of services & 44 & 29 & 66 \\
\hline Description of policies & 36 & 22 & 61 \\
\hline \multicolumn{4}{|l|}{ Reference } \\
\hline Links to search engines & 32 & 24 & 75 \\
\hline Links to Net directories & 23 & 15 & 65 \\
\hline Reference section & 37 & 30 & 81 \\
\hline Links to own OPAC & 42 & 39 & 93 \\
\hline Links to other OPACs & 33 & 27 & 82 \\
\hline Links to local info & 25 & 17 & 68 \\
\hline Subscription encyclopedia & 14 & 13 & 93 \\
\hline \multicolumn{4}{|l|}{ Research } \\
\hline Links to Net subject resources & 30 & 22 & 73 \\
\hline Pathfinders to local resources & 5 & 4 & 80 \\
\hline Links to subscription services & 36 & 33 & 92 \\
\hline Links to free periodicals & 19 & 13 & 68 \\
\hline \multicolumn{4}{|l|}{ Instruction } \\
\hline Net/Net software tutorials & 26 & 18 & 69 \\
\hline Library use tutorials & 14 & 11 & 79 \\
\hline Software tutorials & 3 & 2 & 67 \\
\hline \multicolumn{4}{|l|}{ Functionalities } \\
\hline Request forms & 15 & 10 & 67 \\
\hline Search engines & 3 & 2 & 67 \\
\hline
\end{tabular}

terials on a local level, and what is useful at one library may not be applicable elsewhere within the system or campus.

After level 3, the first appearance of content significantly dropped off. Thirteen items made a first appearance on level 4 , whereas only seven made a first appearance on level 5. On level 4, the item appearing most significantly was the collection of links to Internet directories, appearing here on 38 percent of the sites that offered this content. This is a fair distance from the main page, although if one follows the path from systemwide page to individual library page to departmental page to finding tools page to Internet directories, it does make some sense, although perhaps not to users. The sparsity of new content that appeared on level 5 is illustrated in table 8 .

\section{Discussion and Conclusions}

One major goal in examining these fifty research library and fifty two-year college library Web sites was to discover the purpose these Web sites serve as manifested by their content. These sites might serve four possible purposes: as a tool for information, reference, research, and instruction. Considered as a group, the libraries studied served all these purposes, although each individual site may not have. Individual research library sites, however, were more likely to fulfill all of these purposes, and to fulfill them to a far greater degree, than the sites of two-year college libraries. 
Research library sites contained a greater quantity of what they offered than two-year college libraries. For example, in the case of subject-related Internet resources, forty-one research library sites covered more than twenty subject areas, whereas half the two-year college libraries offering this type of resource covered five or fewer subject areas. Two-year college library sites also were less likely to offer instructional materials on library use, include pathfinders for topical research, or mount their own Internet tutorials. Coverage of reference sources was sparse. Certain individual two-year college library sites were so small that they fulfilled a very limited purpose in a very limited way. Whether these limitations were intentional or necessitated by a lack of resources is a question that must be asked and one that could have been answered had these sites included a mission statement. The lack of such a statement is especially compelling as half these sites either had no update date or had not been updated in about a year.

A small number of two-year college library sites did create their own reference, research, and instructional materials. Overall, however, two-year college sites offered substantial resources only when they linked to the materials and meta-collections mounted by other, larger library sites. Given the hyperlinking nature of the Web, in which site creators are encouraged to link to external resources, it was surprising that this practice was not more widely encountered. Such a practice also can offer access to materials that a small library cannot collect. For example, it may be accepted that students at these colleges have as much need for Internet reference sources and tutorials on Internet use as their counterparts at research institutions. High-quality collections of these resources are not difficult to find or, if need be, to adapt to local conditions.

In the course of this research, the authors searched for a core content that was common to these academic library Web sites. This core was defined as the presence of the item in more than half of the library sites studied. Table 1 demonstrates that the following items constitute a core:

- contact e-mail link;

- update date;

- staff directory;

- description of services;

- links to search engines;

- reference section/links;

- links to the library's own OPAC;

- links to other libraries' OPAC;

- links to Internet subject resources;

- links to subscription database/journal services.

Considering the research libraries separately, the following items can be added:

- physical address;

- library news/events;

- description of departments;

- links to a subscription encyclopedia;

- pathfinders to local resources;

- request forms.

Considering the two-year college libraries separately, the following items can be added:

- description of policies;

- Internet/Internet software tutorials.

This research has shown that there is a core common content that can be identified for academic library Web sites indepen-

\section{TABLE 7}

\section{Links from Main Screen (Level 1) by More Than Half of Research Libraries}

\begin{tabular}{lccc} 
Resource & Total & Total Level 1 & Percentage \\
\hline Contact email link & 50 & 44 & 88 \\
News/events & 44 & 32 & 73 \\
Description of services & 40 & 22 & 55 \\
Links to own OPAC & 50 & 43 & 86 \\
Links to subscription services & 49 & 26 & 53 \\
Request forms & 35 & 19 & 54 \\
Search engine & 29 & 24 & 83 \\
\hline
\end{tabular}




\section{TABLE 8}

New Content Appearing on Level 5

\begin{tabular}{lccc}
\hline Resource & Total Ph.D. & Total Level 5 & Percentage \\
\hline Links to search engines & 38 & 1 & 3 \\
Links to Net directories & 22 & 1 & 5 \\
Reference section & 41 & 1 & 2 \\
Links to local info & 24 & 1 & 4 \\
Subscription encyclopedia & 41 & 1 & 2 \\
Links to Net subject resources & 42 & 2 & 5 \\
Pathfinders to local resources & 30 & 3 & 10 \\
Links to subscription services & 49 & 1 & 2 \\
Net/Net software tutorials & 10 & 1 & 10 \\
\hline
\end{tabular}

dent of the parent institution when research universities and two-year colleges are compared. The general purpose of an academic library Web site is to serve as a tool for information, reference, and research. The departure occurs when one considers scope and scale. The two-year college sites offer fewer resources within a smaller, simpler architectural scheme. The complexity of a Web site, which may require the presence of a site search engine, is related to the complexity of the library and, on a broader scale, of the institution

itself. This was manifested in the research library sites. These larger institutions, for example, make greater use of freely available Internet resources and are more likely to create Web versions of paper documents (pathfinders). As a result, patrons of the more complex libraries-and their Web sites-are asked to select from and use a larger number and variety of materials and to navigate their way through a larger maze of resources. That these Web sites offer a greater number of tutorials is highly appropriate.

\section{Notes}

1. Thomas Dowling, Libweb. Available at <http://sunsite.Berkeley.EDU/Libweb/>.

2. Laurel A. Clyde, "The Library as Information Provider: The Home Page," Electronic Library 14.6 (Dec. 1996): 549-58.

3. Mark Stove and Steven D. Zink, "World Wide Web Home Page Design: Patterns and Anomalies of Higher Education Library Home Pages," Reference Services Review 24 (fall 1996): 7-20.

4. Jan Whalen, "A Study of Library Web Sites" (Nov. 1996). Available at <http://rylibweb.man.ac.uk/ pubs/libraries.html>.

5. David L. King, "Library Home Page Design: A Comparison of Page Layout for Front-ends to ARL Library Web Sites," College E Research Libraries 59 (Sept. 1998): 458-65.

6. Steven W. Sowards, "A Topology of Ready Reference Web Sites in Libraries," First Monday 3 (May 1998). Available at <http://www.firstmonday.dk/issues/issue3_5/sowards/>.

7. Peter A. Bloniarz and Kai R. Larsen, "A Cost Performance Model for Assessing WWW Service Investments" (June1997). Available at <http://www.ctg.albany.edu/projects/inettb/SpreadSheets.html>.

8. Peterson's Register of Higher Education 1998, 11th ed. (Princeton, N..: Peterson's, 1998): 687.

9. Peterson's Guide to Two-Year Colleges 1998, 28th ed. (Princeton, N. J.: Peterson's,1998 ): 464.

10. Digest of Education Statistics 1997, NCES 98-015 by Thomas D. Snyder et al (Washington, D.C.: U.S. Department of Education, National Center for Education Statistics, 1997): 259.

11. Ibid., 183.

12. Ibid., 191.

13. Statistical Abstract of the United States: 1996, $116^{\text {th }}$ ed. (Washington, D.C.: U.S. Bureau of the Census, 1996): 190.

14. Jennifer Cox and Ralph Johnson, "Transfer Students in the Library: The Forgotten Population," Research Strategies 10.2 (spring 1992): 88-91.

15. The list of research university libraries is located at <http://www.rci.rutgers.edu/ still/phd.htm $>$. The list of two-year college libraries is located at <http://www.albany.edu/ lcohen/2year.html>.

16. Patrick J. Lynch, "Site Structure," in Web Style Manual (Yale Center for Advanced Instructional Media, 1996). Available at <http://info.med.yale.edu/caim/manual/sites/site_structure.html>.

17. The DelAWARE site is available at <http://www.lib.de.us/>. 